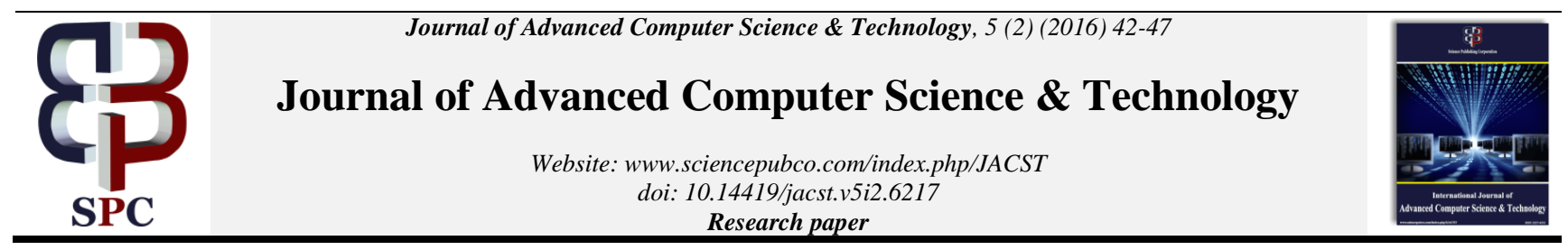

\title{
Effect of subcooling and superheating on performance of a cascade refrigeration system with considering thermo- economic analysis and multi-objective optimization
}

\author{
Mohammad Mehdi Keshtkar* \\ Department of Mechanical Engineering, Kerman Branch, Islamic Azad University, Kerman, Iran. Fax:+983431321010 \\ *Corresponding author E-mail: mkeshtkar54@yahoo.com
}

\begin{abstract}
In present work, effect of degrees of subcooling and superheating based on thermoeconomic optimization is investigated in two stagecascade refrigeration system (TS-CRS). At the first step, by using R717 and R744 as refrigerants, a thermoeconomic analysis is applied to TS-CRS. Based on results of the first section and using the genetic algorithm (GA) optimizer implemented in MATLAB, the optimum operative conditions of a specific TS-CRS is determined. Finally, based on the Pareto frontier obtained from the GA optimization, a decision-making strategy is then used to determine a final solution by TOPSIS method. Two single-objective optimization strategies (SOS), i.e. exergetic optimization and cost optimization, are applied on TS-CRS. The aim of the first strategy is to maximize the exergetic efficiency and the aim of the second strategy is minimizing the total annual cost of the system. The case study results show that, compared to the base design, the use of SOS for maximizing of exergetic efficiency can be increases the exergetic efficiency $94.5 \%$. In addition, the use of the second SOS can decrease the total system cost by $11 \%$. Using MOS compared to base design, exergetic efficiency and the total system cost can be increase by $99.1 \%$ and $28.6 \%$ respectively.
\end{abstract}

Keywords: Subcooling; Superheating; Cascade; Thermoeconomic Optimization; TOPSIS Method.

\section{Introduction}

Multiple stage refrigeration system can be accomplished by using separate systems with the evaporator of the high stage serving as the condenser of the low stage by means of a heat exchanger. This type of system, termed a cascade system, is well adapted to extremely low temperature systems or to any system where the total compression ratio is very large [1]. In many competitive markets like the ultra low temperature freezers, cryogenic storage, liquefaction of natural gas in petrochemical plants, chillers for lasers, recirculating chillers and refrigerated incubators, the production plants are continuously being optimized and new industrial plants designed to be more economical and to deliver products at competitive prices to the market. Cascade systems in multiples of two, three, or even more separate stages make possible refrigeration at almost any desired evaporating or condensing temperature. Since different refrigerants can be used in the separate systems, refrigerants with characteristics suitable for the specific application can be used [2]. Ammonia (R717), as a natural refrigerant has advantageous thermodynamic properties. Decreasing the filling capacity of ammonia refrigeration system and departing ammonia refrigeration system from the public area to reduce the fatalness of ammonia refrigeration system, have pressed the technique of ammonia refrigeration to be changed. One of which is using R717/R744 double working fluids two-stage refrigeration system instead of the traditional R717 low temperature refrigeration system. This refrigeration system minimizes the charge quantity for R717 by filling only in the high-temperature stage. Usually, R744 used as a secondary refrigerant in the low-temperature stage. R744 is a leading option for environmental reasons, and it can be a winner for power consumption. The confidence resulting from recent experience ensures that R744 will be a long-term option in the foreseeable future. The critical temperature of $31{ }^{\circ} \mathrm{C}$ is also often said to be a disadvantage, but like operating pressure, it offers opportunities to do things differently, and in many cases to generate significant advantage over conventional technology [3-7]. Several researchers have investigated the performance of the two-stage cascade refrigeration systems. Eric and Ratts [8] based on the minimization of entropy generation, analyzed a cascade vapor compression cycle, and determined the optimal temperatures with considering superheating, and throttle losses of the cycle. Results for a two-stage system showed that the higher stage and lower stage entropy generation was $56 \%$ and $44 \%$, respectively and also, the two-stage system reduced losses by $78 \%$ in comparison to the single stage system. A numerical investigation for simultaneous cooling and heating applications by a cascaded system with propane based LT cycle and carbon dioxide based HT cycle carried out [8]. They predicted optimum performance of the system in terms of optimum design parameters, like intermediate temperature. At the another work, for maximizing exergy and refrigeration effect of an endoreversible transcritical R744-R290 cascade cycle a thermodynamic analysis has been implemented and optimum intermediate temperature has been determined [9]. Mafi et al. [10] carried out an exergy analysis for multistage cascade refrigeration systems used in olefin plants. For the system components the equations of exergy destruction and exergetic efficiency developed and then the total exergy destruction and the system overall exergetic efficiency obtained. The results showed that, the minimum work depends only on the ambient temperature and the properties of incoming and outgoing process streams. A thermodynamic analysis of R744-R717 cascade refrigeration system carried out [11]. By 
using the design and operating parameters a multi-linear regression analysis in terms of evaporating, condensing, subcooling, superheating, and cascade heat exchanger temperature difference, expressions for maximum COP, an optimum evaporating temperature and an optimum mass flow ratio in the cascade system achieved. Performance evaluation of a R744-R717 cascade refrigeration system and comparison with a HFC two-stage system (R404A) investigated [12]. With considering design parameters, the system analyzed thermodynamically. Results showed that for low evaporating temperatures $\left(-30^{\circ} \mathrm{C}\right.$ to $\left.-50^{\circ} \mathrm{C}\right)$ in commercial refrigeration, a carbon dioxide-ammonia cascade refrigeration system is an interesting alternative to R404A two-stage refrigeration system for energy and environmental reasons. Rezayan and Behbahaninia [13] performed an exergy analysis and thermoeconomic optimization of a R744/R717 cascade refrigeration cycle. At this work, the objective function is the total annual cost of the system. By trade-off between capital cost and the input exergy cost, optimum values of decision variables specified. Thermodynamic analysis of a transcritical R744/R1270 cycle (refrigerants in low temperature (LT)/ high temperature (HT) circuits) for cooling and heating applications, performed [14]. For design parameters, thermal performance calculated for different combinations of design parameters and optimum performance parameters such as $\mathrm{COP}_{\max }, \mathrm{T}_{\mathrm{opt}}$ and mass flows of R744 and R1270 evaluated. At the another work [15] numerical optimization of a transcritical R744 /R1270 cascade refrigeration -heat pump system with economizer in HT cycle carried out. At this work by using paralle compression economization in the HT cycle as the modification to improve the COP of transcritical cascaded systems, simulation for cooling/heating applications carried out. An experimental evaluation of a cascade refrigeration system with R744 and R717 as refrigerants designed and built for freezing process applications [16]. The effect of the operating parameters on the cascade system's performance investigated and the experimental results compared with two-stage system using R717 as refrigerant. Yari and Mahmoudi [17] carried out thermodynamic analysis and optimization of novel ejector-expansion TRCC (transcritical CO2) cascade refrigeration cycle. In this work, two $\mathrm{CO} 2$ cascade refrigeration cycles considered and simulated. In both these cycles, the bottom cycle is a sub-critical $\mathrm{CO} 2$ cycle and the top cycle is an ejectorexpansion transcritical cycle. Thermodynamics analyses on the performance characteristics of the cycles carried out and then a parametric study performed to optimize the performance of each cycle under various operating conditions. Thermo-economic optimization of a cascade refrigeration system, using R404A-R508B as refrigerant, investigated [18]. By using thermo-economic cost balance equation, a simplified cost minimization methodology applied to calculate the economic costs of all internal flows and products of the system. Once these costs evaluated, the system is thermoeconomically evaluated to identify the effects of the design variables on cost of the flows and products. Aminyavari et al. [19] performed exergetic, economic and environmental analyses, and multi-objective optimization of a R744/R717 cascade refrigeration system. The optimal performance parameters achieved by using genetic algorithm method. Two objective functions (the exergetic efficiency and the total cost rate of the system) considered and a set of optimal solutions achieved. Finally, a final optimum point chose using decision-making method. Modeling and optimization of R717/R134a ice thermal energy storage air conditioning systems using two multi-objective optimization algorithms (NSGA-II and MOPSO) studied [20]. The optimal design parameters which lead to the optimal objective functions (exergy efficiency and total cost rate) achieved. By using TOPSIS decision-making method, the optimum point from Pareto frontier of each optimization algorithm selected for both refrigerants.

The objective of present work is to investigate the optimum operative condition of a R744-R717 cascade refrigeration system that operated in specified conditions based on thermo-economic concept and using of NSGA-II optimization algorithm. By using a decision-making method, the optimum point from Pareto frontier of optimization algorithm selected for both circuits. The novelty of this paper includes the suggestions for increasing efficiencies, decreasing total annual cost for a specific TS-CRS with considering the subcooling and super heating effects in low and high temperature circuits. In this regard, at the first step an exergy analysis based on thermo-economic concept is applied to a TS-CRS. The advantage of using exergy method of thermo-economic optimization is that various elements of the system i.e. six parameters including evaporating temperature of carbon dioxide, condensing temperature of ammonia, degrees of subcooling and superheating of carbon dioxide circuit and degrees of subcooling and superheating of ammonia circuit can be optimized separately. At the second step, two SOS (exergetic optimization and cost optimization) and a MOS (balance between exergetic optimization and cost optimization) are performed using NSGA-II optimization algorithm on TS-CRS. For the sake of completeness, after thermo-economic optimization, we try to determine the optimum operative condition based on TOPSIS method for a specified TS-CRS.

\section{Problem description}

A schematic diagram of a R744-R717 TS-CRS, is shown in Fig. 1. The ammonia is the HT cycle working fluid offering high temperature and carbon dioxide is the LT cycle working fluid to provide low temperature refrigeration. For the LT cycle, superheated carbon dioxide vapor at state 1 is compressed to state 2 in the compressor with an isentropic efficiency, $\eta_{\text {LTC }}$ and then cooled to subcooled liquid at state 3 in the cascaded heat exchanger. The subcooled liquid at state 3 is then expanded in an isenthalpic expansion device to state 4 . The useful cooling is achieved by evaporating carbon dioxide from state 4 to state 1 . For the HT cycle, superheated ammonia vapor enters the compressor at pressure $\mathrm{P}_{5}$ at state 5 in which it is compressed to the pressure of $\mathrm{P}_{6}$, with an isentropic efficiency, $\eta_{\text {HTC }}$, subsequently the compressed fluid at state 6 is subcooled in the Condenser to the temperature of $\mathrm{T}_{6}$. The R717 at state 6 enters the expansion valve and expands. A case study is examined for the TS-CRS at basic design and its values are given in Table1.

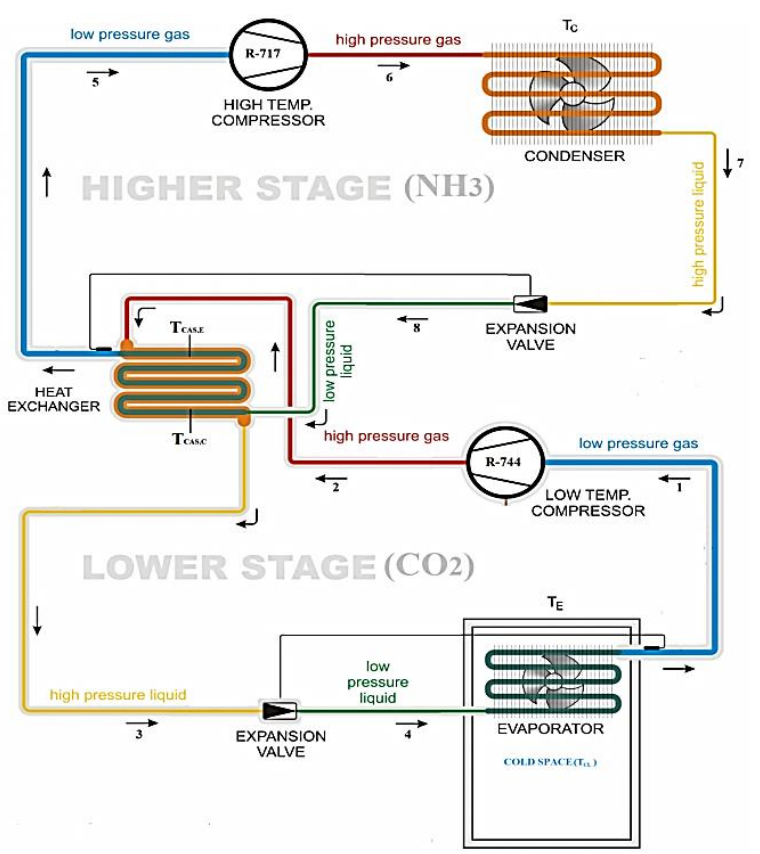

Fig. 1: Shematic of R744-R717 TS-CRS. 
Table 1: Input Parameters Used for Simulation of TS-CRS

\begin{tabular}{|c|c|}
\hline Parameter & Value \\
\hline Refrigeration capacity $\left(\dot{\mathrm{Q}}_{\mathrm{L}}\right)$ & $40 \mathrm{kw}$ \\
\hline Condensing temperature $\left(\mathrm{T}_{\mathrm{C}}\right)$ & $40^{\circ} \mathrm{C}$ \\
\hline Evaporating temperature $\left(\mathrm{T}_{\mathrm{E}}\right)$ & $-50^{\circ} \mathrm{C}$ \\
\hline Temperature difference in cascade condenser $\left(\Delta \mathrm{T}_{\mathrm{CAS}}\right)$ & $5 \mathrm{~K}$ \\
\hline Ambient temperature $\left(\mathrm{T}_{0}\right)$ & $25^{\circ} \mathrm{C}$ \\
\hline Cold room temperature $\left(\mathrm{T}_{\mathrm{CL}}\right)$ & $-30^{\circ} \mathrm{C}$ \\
\hline
\end{tabular}

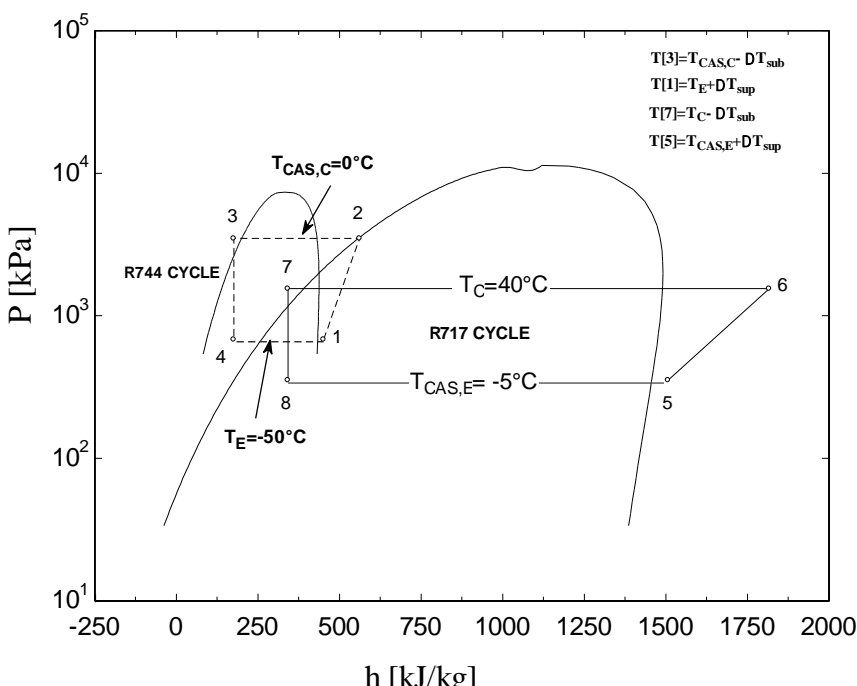

Fig. 2: Pressure-Enthalpy Diagram of R744-R717 TS-CRS with Subcooling and Superheating in Both Cycle.

The refrigeration cascaded system has been modeled employing conservation equations on each individual component of the system. For energy and exergy analyses of TS-CRS, which was shown schematically in Fig. 1, the following sequence of equations was applied:

Evaporator:

$\dot{\mathrm{Q}}_{\mathrm{L}}=\dot{\mathrm{m}}_{\mathrm{L}}\left(\mathrm{h}_{1}-\mathrm{h}_{4}\right)$

$\dot{\mathrm{Ex}}_{\mathrm{D}, \text { evap }}=\left(1-\left(\frac{\mathrm{T}_{0}}{\mathrm{~T}_{\mathrm{cl}}}\right)\right) \dot{\mathrm{Q}}_{\mathrm{L}}+\left(\dot{\mathrm{Ex}}_{4}-\dot{\mathrm{Ex}}_{1}\right)+\dot{\mathrm{w}}_{\text {fan,evap }}$

LTC compressor:

$$
\begin{aligned}
& \dot{\mathrm{W}}_{\mathrm{LTC}, \text { Comp }}=\frac{\dot{\mathrm{m}}_{\mathrm{L}}\left(\mathrm{h}_{2 \mathrm{~s}}-\mathrm{h}_{1}\right)}{\eta_{\mathrm{s}} \eta_{\mathrm{m}} \eta_{\mathrm{e}}}=\frac{\dot{\mathrm{m}}_{\mathrm{L}}\left(\mathrm{h}_{2}-\mathrm{h}_{1}\right)}{\eta_{\mathrm{m}} \eta_{\mathrm{e}}} \\
& \dot{\mathrm{Ex}}_{\mathrm{D}, \mathrm{LTC}, \text { comp }}=\left(\dot{\mathrm{E}}_{1}-\dot{\mathrm{Ex}}_{2}\right)+\dot{\mathrm{W}}_{\mathrm{LTC}, \text { comp }}
\end{aligned}
$$

\section{HTC compressor:}

$$
\begin{aligned}
& \dot{\mathrm{W}}_{\mathrm{HTC}, \text { Comp }}=\frac{\dot{\mathrm{m}}_{\mathrm{H}}\left(\mathrm{h}_{6 \mathrm{~s}}-\mathrm{h}_{5}\right)}{\eta_{\mathrm{s}} \eta_{\mathrm{m}} \eta_{\mathrm{e}}}=\frac{\dot{\mathrm{m}}_{\mathrm{H}}\left(\mathrm{h}_{6}-\mathrm{h}_{5}\right)}{\eta_{\mathrm{m}} \eta_{\mathrm{e}}} \\
& \dot{\mathrm{Ex}}_{\mathrm{D}, \mathrm{HTC}, \mathrm{comp}}=\left(\dot{\mathrm{E}}_{5}-\dot{\mathrm{E}}_{6}\right)+\dot{\mathrm{W}}_{\mathrm{HTC}, \mathrm{comp}}
\end{aligned}
$$

Cascade condenser:

$$
\dot{\mathrm{Q}}_{\text {cas }}=\dot{\mathrm{m}}_{\mathrm{L}}\left(\mathrm{h}_{2}-\mathrm{h}_{3}\right)=\dot{\mathrm{m}}_{\mathrm{H}}\left(\mathrm{h}_{5}-\mathrm{h}_{8}\right), \quad \frac{\dot{\mathrm{m}}_{\mathrm{H}}}{\dot{\mathrm{m}}_{\mathrm{L}}}=\frac{\mathrm{h}_{2}-\mathrm{h}_{3}}{\mathrm{~h}_{5}-\mathrm{h}_{8}}
$$

$$
\dot{\mathrm{Ex}}_{\mathrm{D}, \mathrm{CAS}}=\left(\left(\dot{\mathrm{Ex}}_{2}+\dot{\mathrm{Ex}}_{8}\right)-\left(\dot{\mathrm{Ex}}_{3}+\dot{\mathrm{Ex}}_{5}\right)\right)
$$

Condenser:

$\dot{\mathrm{Q}}_{\mathrm{H}}=\dot{\mathrm{m}}_{\mathrm{H}}\left(\mathrm{h}_{6}-\mathrm{h}_{7}\right)$

$\dot{\mathrm{Ex}}_{\mathrm{D}, \mathrm{cond}}=\left(\frac{\mathrm{T}_{0}}{\mathrm{~T}_{0}}-1\right) \dot{\mathrm{Q}}_{\mathrm{H}}+\left(\dot{\mathrm{Ex}}_{6}-\dot{\mathrm{Ex}}_{7}\right)+\dot{\mathrm{W}}_{\mathrm{fan}, \mathrm{cond}}$

LTC expansion valve:

$\mathrm{h}_{3}=\mathrm{h}_{4}$

$\dot{\mathrm{Ex}}_{\mathrm{D}, \mathrm{LTC}, \exp }=\left(\dot{\mathrm{Ex}}_{3}-\dot{\mathrm{Ex}}_{4}\right)$

HTC expansion valve:

$\mathrm{h}_{7}=\mathrm{h}_{8}$

$\dot{\mathrm{Ex}}_{\mathrm{D}, \mathrm{HTC}, \exp }=\left(\dot{\mathrm{Ex}}_{7}-\dot{\mathrm{Ex}}_{8}\right)$

The result of energy analyses for mentioned conditions was shown schematically in Figure 2. In addition, the coefficient of performance can be expressed as:

$\mathrm{COP}=\frac{\dot{\mathrm{Q}}_{\mathrm{E}}}{\dot{\mathrm{W}}_{\mathrm{H}}+\dot{\mathrm{W}}_{\mathrm{L}}}=\frac{\left(\mathrm{h}_{5}-\mathrm{h}_{8}\right)\left(\mathrm{h}_{1}-\mathrm{h}_{4}\right)}{\left(\mathrm{h}_{6}-\mathrm{h}_{5}\right)\left(\mathrm{h}_{2}-\mathrm{h}_{3}\right)+\left(\mathrm{h}_{5}-\mathrm{h}_{8}\right)\left(\mathrm{h}_{2}-\mathrm{h}_{1}\right)}$

The total inlet exergy into the system can be expressed as:

$\dot{\mathrm{Ex}}_{\mathrm{in}}=\dot{\mathrm{W}}_{\mathrm{LTC}, \mathrm{comp}}+\dot{\mathrm{W}}_{\mathrm{HTc}, \mathrm{comp}}+\dot{\mathrm{W}}_{\text {fan,evap }}+\dot{\mathrm{W}}_{\text {fan,cond }}$

And the outlet exergy of the system can also be determined as:

$\dot{\mathrm{Ex}}_{\text {out }}=\left(\frac{\mathrm{T}_{0}}{\mathrm{~T}_{\mathrm{CL}}}-1\right) \dot{\mathrm{Q}}_{\mathrm{L}}$

(2) Finally, exergy destruction and exergetic efficiency of the overall system can be obtained by (Kotas, 1995):

$\dot{\mathrm{Ex}}_{\mathrm{D}, \text { total }}=\dot{\mathrm{E}} \mathrm{x}_{\text {in }}-\dot{\mathrm{E}} \mathrm{x}_{\text {out }}$

$\eta_{\text {II }}=\frac{\dot{\mathrm{Ex}}_{\text {Out }}}{\dot{\mathrm{Ex}}_{\text {in }}}=1-\left(\frac{\dot{\mathrm{Ex}}_{\mathrm{D}, \text { total }}}{\dot{\mathrm{Ex}}_{\text {in }}}\right)$

Based on the model created above, thermo-economic optimization can be applied on the TS-CRS. Six independent parameters were selected as decision variables, which are listed in Table 2. Also, for each of design parameters the range of variation, were applied as constraints to optimization problem are shown. In this study, the imposed optimization constraints of the key design variables were determined based on the recommended values from the practical engineering projects. 
Table 2: Decision Variables for TS-CRS and Their Corresponding Range Of Variation

\begin{tabular}{ll}
\hline Range of variation & decision variables \\
\hline$-55^{\circ} \mathrm{C}<\mathrm{T}_{\mathrm{E}}<-45^{\circ} \mathrm{C}$ & $\begin{array}{l}\text { condensing temperature of } \\
\text { ammonia } \\
\text { evaporating temperature of } \\
\text { carbon dioxide } \\
\text { degree of superheating at } \\
\text { carbon dioxide circuit } \\
\text { degree of subcooling at car- } \\
\text { bon dioxide circuit } \\
\text { degree of superheating at } \\
0[\mathrm{k}]<\Delta \mathrm{T}_{\text {Sup, LTC }}<10[\mathrm{k}]\end{array}$ \\
$0[\mathrm{k}]<\Delta 0^{\circ} \mathrm{C}$ sub, LTC $<8[\mathrm{k}]$ & $\begin{array}{l}\text { ammonia circuit } \\
\text { degree of subcooling at am- } \\
\text { monia circuit }\end{array}$ \\
$0[\mathrm{k}]<\Delta \mathrm{T}_{\text {Sup, HTC }}<10[\mathrm{k}]$ & \\
$0[\mathrm{k}]<\Delta \mathrm{T}_{\text {Sub }, \text { HTC }}<8[\mathrm{k}]$ &
\end{tabular}

\section{Results and discussions}

Optimization strategy for TS-CRS proposed in this study consists of three steps. The first step is to use a sensitivity analysis method to detect the effect of some design parameters on objective functions. In the second step through genetic algorithm optimizer (two single-objective optimization strategy (SOS), i.e. exergetic optimization and cost optimization, and a multi-objective optimization strategy (MOS)), to search for a set of Pareto optimal solutions based on the two objective functions defined and the mathematic model of the TS-CRS as well as the constraints defined for each key design variables. The third step is the decision-making process to determine the desired optimal solution among a set of Pareto optimal points. In the present work, optimization step has been developed in MATLAB Software and making-decision carried out by an EXCEL program that created by author. Finally, the numerical results have been given in the following sections. The exergy destruction of all components of the TS-CRS for two cases (without subcooling and both subcooling and superheating) at various cooling loads are summarized in Fig. 3. It was found that the exergy destruction rate of the condenser is dominant over all other irreversibilities in the cycle. The evaporator, LTC compressor, HTC compressor, cascade heat exchanger, LTC expansion valve and HTC expansion valve have the next highest amounts of exergy destruction rates, respectively. According to the second law analysis, it is demonstrates that significant improvements exist in the condenser. In addition from these figures observed that, the exergy destruction rates of all components increases with the cooling load. It is noticeable that, decreasing the subcooling results in increasing the exergy destruction rates of all components, but these variations is negligible.

a)

$$
\Delta T_{\text {sub }}=8 K, \Delta T_{\text {sup }}=10 K
$$

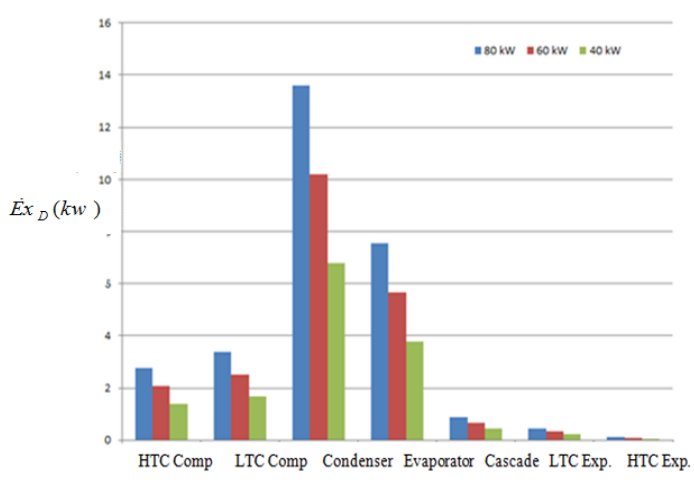

b)

$\Delta T_{\text {sub }}=0, \Delta T_{\text {sup }}=10 K$

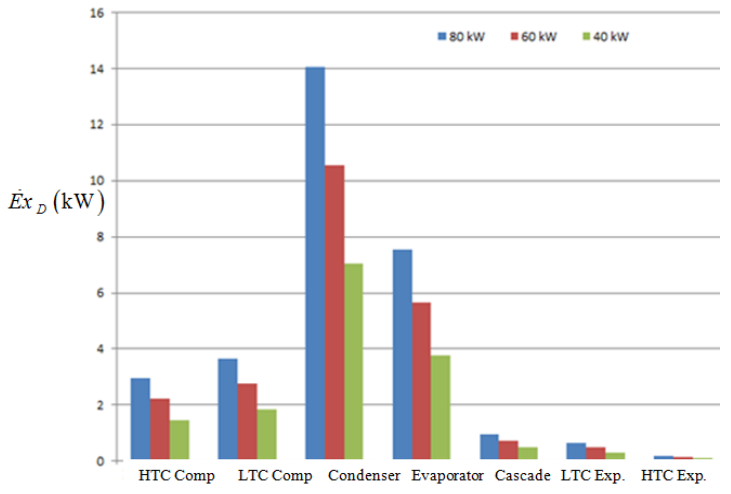

Fig. 3: The Exergy Destruction Rates in Different Components of TS-CRS for Different Cooling Loads.

Fig. 4 (a) and (b) show the effect of changing R717 condensing temperature, $T_{C}$, on costs of components of TS-CRS for different subcooling and superheating degrees in both cycle. It is observed that, by decreasing $T_{C}$, the cost of air-cooled condenser increases due to the decrease of the logarithmic temperature difference between ambient temperature and condensation temperature. On the other hand, the cost of HTC compressor shows an increasing trend due to increase of the pressure ratio. Costs of other system components do not change considerably. By comparison of Fig. 4 (a) and (b), the effect of changing subcooling and superheating degrees in both cycle on costs of components of the TS-CRS is clarified. As can be seen, by increasing $\Delta \mathrm{T}_{\text {sub }}$ from 0 to $8 \mathrm{~K}$ and $\Delta \mathrm{T}_{\text {sup }}$ from $10 \mathrm{~K}$ to $20 \mathrm{~K}$, the evaporator cost shows a decreasing trend, while condenser and cascade condenser costs show an increasing trend. The costs of LTC and HTC also remain constant, due to the effect of variation of superheating and subcooling degrees at the compressors is negligible on the compressor cost.

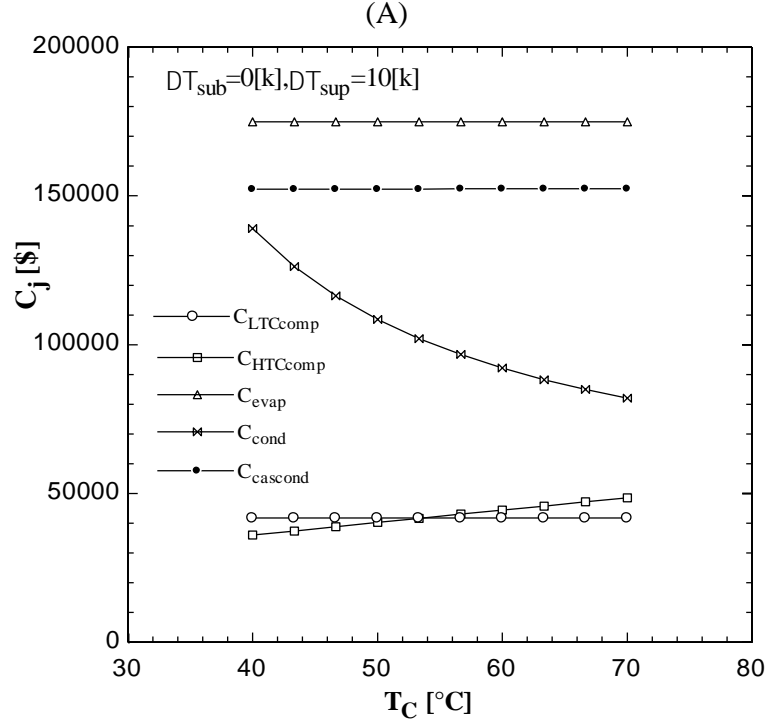

(B) 


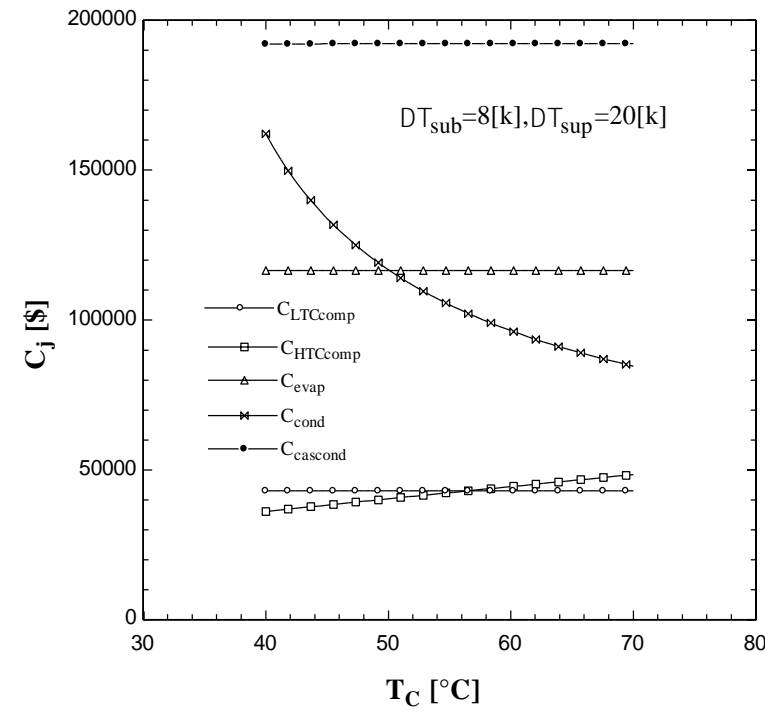

Table 3 shows the results at final optimum design point derived from TOPSIS decision-making method at different strategies. At the based design for two cases (without and with subcooling/superheating) the exergetic efficiency, total cost and needed work in HTC and LTC compressors achieved. At the next step for three-optimization strategy, i.e. single objective based on exergetic efficiency, single objective based on total cost and finally, multiobjective strategy based on exergetic efficiency- total cost the mentioned parameters calculated. The results show that, for strategy (1) with respect to state (2), the exergetic efficiency increases $94.5 \%$, total cost increases $38.7 \%$ and needed work in HTC and LTC compressors decrease $14.66 \%$ and $21.6 \%$, respectively. In addition, for strategy (2) with respect to state (2), the exergetic efficiency increases $21 \%$, total cost and needed work in HTC and LTC compressors decrease $11 \%, 15.2 \%$ and $18 \%$, respectively. For strategy (3), it is observed that the exergetic efficiency increases $99.1 \%$, total cost increases $28.6 \%$ and needed work in HTC and LTC compressors decrease $21 \%$ and $25.6 \%$ with respect to state (2), respectively.

Fig. 4: Effect of Variations of R717 Condensing Temperature on Costs of System Components $\left(\mathrm{T}_{\mathrm{E}}=-50^{\circ} \mathrm{C}, \Delta \mathrm{T}_{\mathrm{cas}}=5 \mathrm{~K}, \mathrm{~T}_{\mathrm{cas}, \mathrm{E}}=-5^{\circ} \mathrm{C}\right)$.

Table 3: Results at Final Optimum Design Point Derived from TOPSIS Decision-Making Method at Different Strategies.

\begin{tabular}{|c|c|c|c|c|c|c|}
\hline Parameter & unit & $\begin{array}{l}\text { State (1) } \\
\Delta \mathrm{T}_{\text {sub }}=0 \\
\Delta \mathrm{T}_{\text {sup }}=0\end{array}$ & $\begin{array}{l}\text { d design } \\
\text { State (2) } \\
\Delta \mathrm{T}_{\text {sub }}=8 \mathrm{~K} \\
\Delta \mathrm{T}_{\text {sup }}=20 \mathrm{~K}\end{array}$ & $\begin{array}{l}\text { Strategy (1): } \\
\text { SOS based on } \\
\text { exergetic effi- } \\
\text { ciency }\end{array}$ & $\begin{array}{l}\text { Strategy (2): } \\
\text { SOS based on } \\
\text { Total cost }\end{array}$ & $\begin{array}{l}\text { Strategy (3): } \\
\text { MOS based on } \\
\text { exergetic effi- } \\
\text { ciency \& Total } \\
\text { cost }\end{array}$ \\
\hline $\begin{array}{l}\text { Condensing tempera- } \\
\text { ture }\left(\mathrm{T}_{\mathrm{C}}\right)\end{array}$ & {$\left[{ }^{\circ} \mathrm{C}\right]$} & 45 & 45 & 40.34 & 40.63 & 40.92 \\
\hline $\begin{array}{l}\text { Evaporating tempera- } \\
\text { ture }\left(\mathrm{T}_{\mathrm{E}}\right)\end{array}$ & {$\left[{ }^{\circ} \mathrm{C}\right]$} & -50 & -50 & -46.96 & -45.98 & -45 \\
\hline $\begin{array}{l}\text { Subcooling in } \mathrm{HT} \\
\text { circuit }\left(\Delta \mathrm{T}_{\mathrm{Sub}, \mathrm{H}}\right)\end{array}$ & {$[\mathrm{k}]$} & 0 & 10 & 9.99 & 0.422 & 9.998 \\
\hline $\begin{array}{l}\text { Subcooling in } \mathrm{LT} \\
\text { circuit }\left(\Delta \mathrm{T}_{\text {sub }, \mathrm{L}}\right)\end{array}$ & {$[\mathrm{k}]$} & 0 & 8 & 8 & 1.89 & 7.98 \\
\hline $\begin{array}{l}\text { Superheating in } \mathrm{HT} \\
\text { circuit }\left(\Delta \mathrm{T}_{\text {sup }, H}\right)\end{array}$ & {$[\mathrm{k}]$} & 0 & 20 & 1.35 & 1.95 & 0.9 \\
\hline $\begin{array}{l}\text { Superheating in } \mathrm{LT} \\
\text { circuit }\left(\Delta \mathrm{T}_{\text {sup }, \mathrm{L}}\right)\end{array}$ & {$[\mathrm{k}]$} & 0 & 10 & 1.02 & 1.85 & 2.32 \\
\hline Total cost $\left(\mathrm{C}_{\text {total }}\right)$ & {$[\$]$} & 221262 & 115389 & 160074 & 103453 & 148410 \\
\hline $\begin{array}{l}\text { Exergetic efficiency } \\
\left(\eta_{\text {II }}\right)\end{array}$ & $(\%)$ & 20.31 & 21.35 & 41.59 & 25.76 & 42.60 \\
\hline $\begin{array}{l}\text { Work in HT compres- } \\
\text { sor }\left(\mathrm{W}_{\mathrm{H}}\right)\end{array}$ & {$[\mathrm{kw}]$} & 20.32 & 19.78 & 15.66 & 16.76 & 15.61 \\
\hline $\begin{array}{l}\text { Work in LT compres- } \\
\text { sor }\left(\mathrm{W}_{\mathrm{L}}\right)\end{array}$ & {$[\mathrm{kw}]$} & 24.27 & 22.64 & 17.74 & 18.48 & 16.84 \\
\hline
\end{tabular}

\section{Conclusion}

In this study thermoeconomic optimization of a R717/R744 cascade refrigeration system is presented. Based on the Pareto frontier obtained from the GA optimization, a decision-making strategy is then used to determine a final solution by TOPSIS method. Two single-objective optimization strategies (SOS), i.e. exergetic optimization and cost optimization, and one multi-objective optimization strategy (MOS) are applied on TS-CRS. The aim of the first SOS is to maximize the exergetic efficiency and the aim of the second SOS is minimizing the total annual cost of the system. The results shows by increasing $\Delta \mathrm{T}_{\mathrm{sub}, \mathrm{L}}$ or $\Delta \mathrm{T}_{\mathrm{sub}, \mathrm{H}}$, exergetic efficiency and annual total cost of the cascade refrigeration system increase. The results from simulation of a specified TS-CRS show that, compared to the base design, the use of the first SOS can be increases the exergetic efficiency. In addition, a reduction in the consumption of work in HTC and the LTC achieved. In addition, the use of the second SOS can increase the exergetic efficiency and decrease the total system cost and consumption of work in HTC and LTC decrease. Using MOS to achieve a best balance between thermodynamic efficiency and economic cost performed to determine the optimal value of the various design parameters of the system. Compared to base design, exergetic efficiency and the total system cost can be increase by $99.1 \%$ and $28.6 \%$ respectively and $46.6 \%$ more energy can be saved by using MOS in compressors.

\section{References}

[1] Getu HM, Bansal PK. "Simulation model of a low temperature supermarket refrigeration system". Int. J. HVAC \& R, Res. 12 (4), (2006), pp.1117-1139.

[2] Pearson A." New development in industrial refrigeration", ASHRAE Journal. (2001), pp.54-58. 
[3] Christensen KG, Bertilsen P. "Refrigeration systems in supermarkets with propane and CO2-energy consumption and economy". 21 st International Congress of Refrigeration, Washington DC, (2003), pp.1-10.

[4] Ge YT, Tassou SA. Control Optimisation of CO2 Cycles for Medium Temperature Retail Food Refrigeration Systems. Int. J. Refrigeration. 32 (6), (2009), pp.1376-1387.

[5] Wilson I, Maier D. "Carbon dioxide for use as a refrigerant". In: Refrigeration Science and Technology, Proceedings, IIR IRHACE Conference, Innovative Equipment and Systems for Comfort and Food Preservation. The University of Auckland, (2006), pp.305311.

[6] Ratts EB, Brown JS. "A generalized analysis for cascading single fluid vapor compression refrigeration cycles using anentropy generation minimization method". Int. J. Refrigeration. 23, (2000), pp.353-365.

[7] Sawalha S. "Using CO2 in supermarket refrigeration". ASHRAE J. 47 (8), (2005),pp.26-30.

[8] Eric B, Ratts S. "A generalized analysis for cascading single fluid vapor compression refrigeration cycles using an entropy generation minimization method", Int. J. Refrigeration. 23,( 2000,) pp.353365.

[9] Bhattacharyya S, Mukhopadhyay A, Kumar SA, Sarkar J. "Optimization of CO2-C3H8 cascade system for refrigeration and heating", Int. J. Refrigeration, 28, ( 2005), pp.1284-1292.

[10] Mafi M, Mousavi Naeynian SM, Amidpour M. "Exergy analysis of multistage cascade low temperature refrigeration systems used in olefin plants", Int. J. Refrigeration, 32 (2), ( 2009), pp.279-294.

[11] Getu HM, Bansal PK. "Thermodynamic analysis of an R744-R717 cascade refrigeration system", Int. J. Refrigeration, 31 (1), (2008), pp.45-54.

[12] Messineo A. "R744-R717 Cascade refrigeration system: performance evaluation compared with a HFC two-stage system", Energy Proc. 14, (2012), pp.56-65.

[13] Rezayan O, Behbahaninia A. "Thermoeconomic optimization and exergy analysis of $\mathrm{CO} 2 / \mathrm{NH} 3$ cascade refrigeration systems", J. Energy. 36, (2011), pp.888-895.

[14] Dubey AM, Kumar S, Agrawal GD. "Thermodynamic analysis of a transcritical CO2/propylene (R744-R1270) cascade system for cooling and heating applications", Energy Conversion and Management. 86, (2014), pp.774-783.

[15] Dubey AM, Kumar S. "Numerical optimization of a transcritical $\mathrm{CO} 2 /$ propylene cascaded refrigeration-heat pump system with economizer in HT cycle", J. Indian Academy of Sciences. 40 (2), (2015), pp.437-454.

[16] Dopazo JA, Seara JF. "Experimental evaluation of a cascade refrigeration system prototype with $\mathrm{CO} 2$ and $\mathrm{NH} 3$ for freezing process applications", Int. J. Refrigeration, 34 (1), (2011), pp. 257-267.

[17] Yari M, Mahmoudi SMS. "Thermodynamic analysis and optimization of novel ejector-expansion TRCC (transcritical CO2) cascade refrigeration cycles (Novel transcritical CO2 cycle)" , J. Energy, 36 , (2011), pp. 6839-6850.

[18] Parekh AD, Tailor RP." Thermoeconomic Optimization of Cascade Refrigeration System using Refrigerant Pair R404A-R508B", Applied Mechanics and Materials. 110, (2012), pp.677-684.

[19] Aminyavari M, Najafi B, Shirazi S, Rinaldi F." Exergetic, economic and environmental (3E) analyses, and multiobjective optimization of a CO2/NH3 cascade refrigeration system", Applied Thermal Engineering. 65, (2014), pp.42-50.

[20] Rahdar MH, Heidari M, Ataei A, Choi JK. "Modeling and optimization of R-717 and R-134a ice thermal energy storage air conditioning systems using NSGA-II and MOPSO algorithms," Applied Thermal Engineering. 96, (2016), pp.217-227. 